TAIWANESE JOURNAL OF MATHEMATICS

Vol. 6, No. 4, pp. 475-498, December 2002

This paper is available online at http://www.math.nthu.edu.tw/tjm/

\title{
CERTAIN CLASSES OF INFINITE SUMS EVALUATED BY MEANS OF FRACTIONAL CALCULUS OPERATORS ${ }^{\not}$
}

\author{
Shy-Der Lin, Shih-Tong Tu and H. M. Srivastava
}

\begin{abstract}
In several recent works, many different families of infinite series were evaluated by applying certain operators of fractional calculus (that is, calculus of derivatives and integrals of any arbitrary real or complex order). In the present sequel to some of these recent investigations, it is observed that much more general classes of infinite sums can be derived without using fractional calculus. Some other related evaluations of finite and infinite sums are also considered.
\end{abstract}

\section{INTRODUCTION}

The subject of fractional calculus (that is, calculus of derivatives and integrals of any arbitrary real or complex order) has gained importance and popularity during the past three decades or so, due mainly to its demonstrated applications in many seemingly diverse fields of science and engineering (see, for details, [3] and [12]). Indeed one of the most frequently encountered tools in the theory and applications of fractional calculus is furnished by the Riemann-Liouville (fractional differintegral) operator $\mathrm{D}_{\mathrm{z}}^{1}$ defined by (cf., e.g., [6] and [12])

$$
D_{z}^{1} f f(z) g:= \begin{cases}\frac{1}{\Gamma\left(i^{1}\right)} \int_{0}^{z}\left(z i^{3}\right)^{i^{1}} i^{1} f\left({ }^{3}\right) d^{3} & \left(\Re\left({ }^{1}\right)<0\right) \\ \frac{d^{m}}{d z^{m}} D_{z}^{1} i m_{f f}(z) g & (m ; 1 \leqq \Re(1)<m ; m 2 N) ;\end{cases}
$$

Received August 31, 2001.

Communicated by S.-B. Hsu.

2000 Mathematics Subject Classification: 26A33, 33C20; Secondary 33B15.

Key words and phrases: Fractional calculus, infinite series, Riemann-Liouville operator, fractional derivative, fractional integral, generalized Leibniz rule, hypergeometric functions, expansion formula, reduction formula, harmonic numbers, recurrence (or contiguous-function) relations, combinatorial identity, Hurwitz-Lerch Zeta function, Psi (or Digamma) function, summation formulas.

${ }^{\mathrm{a}}$ Invited paper 
provided that the integral in (1.1) exists, $\mathrm{N}$ being (as usual) the set of positive integers.

Recently, by applying the following (essentially equivalent) definition of a fractional differintegral (that is, fractional derivative and fractional integral) of order o 2 R, Nishimoto et al. [11] derived the sums of two interesting families of infinite series which we reproduce here, in slightly modified forms, as Theorem 1 and Theorem 2 below.

Definition ( $c f$. [7], [8], and [17]). If the function $\mathbf{f}(\mathbf{z})$ is analytic (regular) inside and on $\mathrm{C}$, where

$$
\mathrm{C}:=\mathrm{fCi} ; \mathrm{C}^{+} \mathrm{g}
$$

$\mathrm{C} i$ is a contour along the cut joining the points $z$ and $i \mathbf{1}+\mathrm{i} \mathfrak{J}(\mathbf{z})$, which starts from the point at $i 1$, encircles the point $z$ once counter-clockwise, and returns to the point at $\mathbf{i} 1, \mathrm{C}^{+}$is a contour along the cut joining the points $\mathbf{z}$ and $1+\mathrm{i} \mathfrak{J}(\mathbf{z})$, which starts from the point at 1 , encircles the point $Z$ once counter-clockwise, and returns to the point at 1 ,

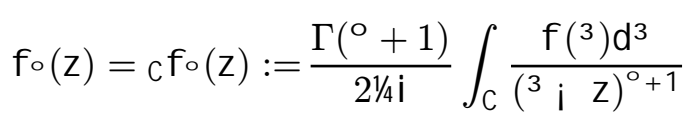

$$
\text { (o } \left.2 \operatorname{RnZi}^{\mathrm{i}} ; \mathrm{Z}^{\mathrm{i}}:=\mathrm{f}_{\mathrm{i}} 1 ; \mathrm{i} 2 ; \mathrm{i} 3 ;:: \mathrm{g}\right)
$$

and

$$
f_{i n}(z):=\lim _{o !} f_{n} f_{o}(z) g \quad(n 2 N) \text {; }
$$

where ${ }^{3} 6 z$;

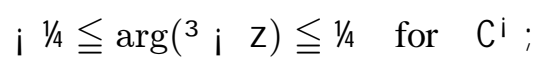

and

$$
0 \leqq \arg \left({ }^{3} \mathrm{i} \quad \mathrm{z}\right) \leqq 2^{1 / 4} \text { for } \mathrm{C}^{+}
$$

then $\mathrm{f}_{\mathrm{o}}(\mathbf{z})(\underline{\mathrm{o}}>0)$ is said to be the fractional derivative of $\mathrm{f}(\mathbf{z})$ of order $\underline{\mathrm{o}}$ and $\mathrm{f}_{\mathrm{o}}(\mathbf{z})(\underline{\mathrm{o}}<0)$ is said to be the fractional integral of $\mathrm{f}(\mathbf{z})$ of orde $\mathbf{i} \stackrel{\mathrm{o}}{\text {, provided }}$ that

$$
\text { jfo }(\mathrm{z}) \mathrm{j}<1 \quad \text { (o } 2 \mathrm{R}) \text { : }
$$


Theorem 1 (cf. Nishimoto et al. [11, p. 92, Theorem 1]). Let $\mathrm{C}$ and $\mathrm{z}$ be complex numbers. Then

$$
\sum_{k=2}^{1} \frac{(\mathrm{i} \mathrm{c})^{\mathrm{k}}}{\mathrm{k}(\mathrm{ki} \mathrm{1)}} \Phi \frac{\mathrm{kz} \mathrm{i} \mathrm{c}}{(\mathrm{zi} \mathrm{c})^{\mathrm{k} i 1}}=\mathrm{c}^{2}
$$

provided that

$$
\left|\frac{\mathrm{c}}{\mathrm{zi} \mathrm{c}}\right|<1 \quad(\mathrm{c} ; \mathrm{z} 2 \mathrm{C})
$$

Theorem 2 ( $\mathrm{cf}$. Nishimoto et al. [11, p. 93, Theorem 2]). For complex parameters $\mathrm{a}$; $\mathrm{b}$; and $\mathrm{c}$;

$$
\begin{aligned}
& \sum_{k=1}^{1} \frac{(k+c+a i 1) \Gamma\left(k+a+b_{i} 1\right)}{k !}\left(i \frac{c}{b_{i} c}\right)^{k} \\
& =\Gamma(a+b i 1)\left\{\left(a i \frac{1}{b i} \frac{c}{b}\right)^{a+b} i(c+a i 1)\right\}
\end{aligned}
$$

provided that

$$
\operatorname{maxfj} \Gamma(k+a) j ; j \Gamma(k+a+b i \quad 1) j g<1 \quad(a ; b 2 C ; k 2 N)
$$

and

$$
\left|\frac{\mathrm{c}}{\mathrm{b}_{\mathrm{i}} \mathrm{c}}\right|<1 \quad(\mathrm{~b} ; \mathrm{c} 2 \mathrm{C})
$$

The proof of each of their results (Theorem 1 and Theorem 2 above) by Nishimoto et al. [11] is based rather heavily upon several lemmas and properties involving the fractional differintegrals of logarithm and power functions (and, in the case of Theorem 2, also upon the generalized Leibniz rule for the differintegral of the product of two functions), which are defined by (1.3). For the sake of completeness, we find it to be worthwhile to recall here each of these potentially useful lemmas and properties associated with the fractional differintegration which is defined above (cf ., e:g., [7] and [8]).

Lemma 1 (Linearity Property). If the functions $\mathbf{f}(\mathbf{z})$ and $\mathbf{g}(\mathbf{z})$ are singlevalued and analytic in some domain $\Omega \mu \mathrm{C}$; then

$$
\left(k_{1} f(z)+k_{2} g(z)\right) \circ=k_{1} f_{\circ}(z)+k_{2} g_{\circ}(z) \quad(\circ 2 R ; z 2 \Omega)
$$

for any constants $\mathrm{k}_{1}$ and $\mathrm{k}_{2}$. 
Lemma 2 (Index Law). If the function $\mathbf{f}(\mathbf{z})$ is single-valued and analytic in some domain $\Omega \mu \mathrm{C}$; then

$$
\begin{aligned}
& \left(f_{1}(z)\right)_{\circ}=f_{1}+\circ(z)=\left(f_{\circ}(z)\right)_{1} \\
& \left(f_{1}(z) 60 ; \quad f_{\circ}(z) 60 ; \quad 1 ; ㅇ R ; \quad z 2 \Omega\right):
\end{aligned}
$$

Lemma 3 (Generalized Leibniz Rule). If the functions $\mathbf{f}(\mathbf{z})$ and $\mathbf{g}(\mathbf{z})$ are single-valued and analytic in some domain $\Omega \mu \mathrm{C}$; then

$$
(\mathrm{f}(\mathrm{z}) \phi \mathrm{g}(\mathrm{z})) \stackrel{\mathrm{o}}{=} \sum_{\mathrm{n}=0}^{1}\left(\begin{array}{l}
\underline{\mathrm{o}} \\
\mathrm{n}
\end{array}\right) \mathrm{f}_{o_{i}} \mathrm{n}(\mathrm{z}) \phi g_{\mathrm{n}}(\mathrm{z}) \quad(\underline{\mathrm{o}} 2 \mathrm{R} ; \mathrm{z} 2 \Omega) ;
$$

where $\mathrm{g}_{\mathrm{n}}$ is the ordinary derivative of $\mathrm{g}(\mathrm{z})$ of order $\mathrm{n}\left(\mathrm{n} 2 \mathrm{~N}_{0}:=\mathrm{N}[\mathrm{f} 0 \mathrm{~g})\right.$; it being tacitly assumed (for simplicity) that $\mathrm{g}(\mathrm{z})$ is the polynomial part (if any) of the product $\mathrm{f}(\mathrm{z}) \mathrm{\phi g}(\mathrm{z})$.

Property 1. For constants $\mathrm{C}$; ; and $\mathrm{o}$;

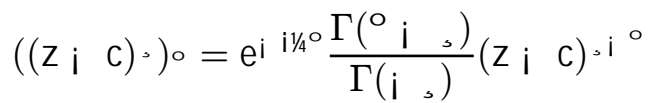

$$
\begin{aligned}
& \text { (ㅇ } 2 \text { R; c; z } 2 \text { C; j } \Gamma(\underline{\mathrm{o}} \mathrm{i},)=\Gamma(\mathrm{i},) \mathrm{j}<1 \text { ): }
\end{aligned}
$$

Property 2. For constants $\mathrm{C}$ and $\stackrel{\mathrm{o}}{\text {; }}$

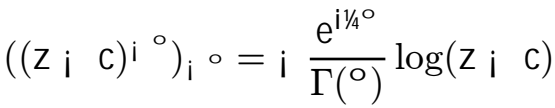

$$
\begin{aligned}
& \text { (ㅇ } 2 \text { R; c; z } 2 \text { C; j } \Gamma(\underline{o}) \mathrm{j}<1 \text { ): }
\end{aligned}
$$

Property 3. For constants $\mathrm{C}$ and $\stackrel{\mathrm{O}}{\text {; }}$

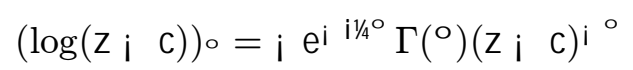

$$
\text { (ㅇ } 2 \text { R; c; z } 2 \text { C; j } \Gamma(\underline{o}) \mathrm{j}<1 \text { ): }
$$

Subsequently, Salinas de Romero and Srivastava [14] demonstrated that, not only each of the assertions of Theorems 1 and 2, but much more general families of infinite sums can also be evaluated without using the aforementioned fractional differintegral operator defined by (1.3). In fact, the only tool employed by Salinas de Romero and Srivastava [14], in their alternative derivation of Theorem 1 and its generalizations without using fractional calculus, is the familiar expansion formula:

$$
\log (1+\mathrm{z})=\sum_{\mathrm{k}=1}^{1} \frac{(\mathrm{i} 1)^{\mathrm{k}+1}}{\mathrm{k}} \mathrm{z}^{\mathrm{k}}=\mathrm{z} \mathrm{i} \sum_{\mathrm{k}=1}^{1} \frac{(\mathrm{i} 1)^{\mathrm{k}+1}}{\mathrm{k}+1} \mathrm{z}^{\mathrm{k}+1} \quad(\mathrm{jzj}<1)
$$


or its obvious variation given by

$$
\begin{aligned}
\log (1+z)= & \sum_{k=1}^{m_{i} 1} \frac{(i 1)^{k+1}}{k} z^{k} i \sum_{k=0}^{1} \frac{(i 1)^{k+m}}{k+m} z^{k+m} \\
& (j z j<1 ; m 2 N)
\end{aligned}
$$

where (and throughout this paper) an empty sum is interpreted (as usual) to be zero. On the other hand, Theorem 2 as well as its natural generalization were shown (by Salinas de Romero and Srivastava [14]) to be simple consequences of the following known hypergeometric reduction formula (cf ., e:g:, [4] and [15, p. 39, Equation (6)]):

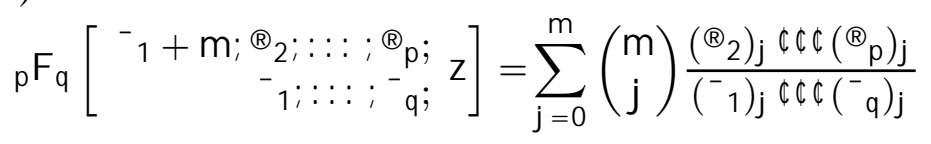

$$
\begin{aligned}
& \phi^{j} \text { pi } 1_{1} F_{\text {qi } 1}\left[\begin{array}{l}
\mathbb{R}_{2}+j ;::: ; \mathbb{R}_{p}+j ; z \\
-2+j ;:: ;{ }^{-}+j ;
\end{array}\right] \text {; }
\end{aligned}
$$

which holds true whenever each member exists. Here $\mathrm{pF}_{\mathrm{q}}$ denotes a generalized hypergeometric function with $\mathrm{p}$ numerator and $\mathrm{q}$ denominator parameters, defined by (cf. [1, Chapter 4])

$$
\begin{aligned}
& \mathrm{pF}_{\mathrm{q}}\left(\AA_{1} ;::: ; \AA_{\mathrm{p}} ;{ }^{-}{ }_{1} ;::: ;{ }_{\mathrm{q}}^{-} ; \mathrm{z}\right) \\
& ={ }_{\mathrm{p}} \mathrm{F}_{\mathrm{q}}\left[\begin{array}{c}
\mathbb{\circledR}_{1} ;::: \mathbb{\circledR}_{\mathrm{p}} ; \mathrm{z} \\
-{ }_{1} ;:: ;{ }_{\mathrm{q}} ;
\end{array}\right]
\end{aligned}
$$

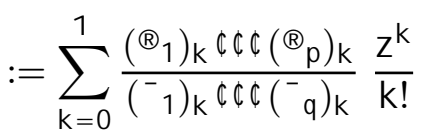

$\left(\mathrm{p} ; \mathrm{q} 2 \mathrm{~N}_{0} ; \quad \mathrm{p} \leqq \mathrm{q}+1 ; \quad \mathrm{p} \leqq \mathrm{q}\right.$ and $\mathrm{jzj}<1 ;$

$$
\mathrm{p}=\mathrm{q}+1 \text { and } \mathrm{jzj}<1 ; \mathrm{p}=\mathrm{q}+1 ; \mathrm{jzj}=1 ; \quad \text { and } \mathfrak{R}(!)>0) ;
$$

where (and in what follows) $\left(\mathrm{S}_{\mathrm{k}}\right.$ denotes the Pochhammer symbol (or the shifted factorial, since $\left.(1)_{k}=k !\left(k 2 N_{0}\right)\right)$ given by

$$
(,)_{k}:=\frac{\Gamma(\lrcorner+k)}{\Gamma(\lrcorner)}=\left\{\begin{array}{lr}
1 & (k=0) \\
,(,+1) \phi \varnothing \Phi(,+k i 1) & (k 2 N)
\end{array}\right.
$$


and

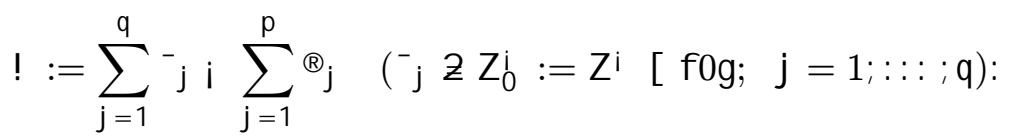

First of all, following Salinas de Romero and Srivastava [14], we denote, for convenience, the infinite series in (1.8) by $\mathrm{S}$. Then, upon replacing the summation index $\mathrm{k}$ by $\mathrm{k}+1$; it is easily seen that

$$
\begin{aligned}
& \mathrm{S}:=\sum_{\mathrm{k}=2}^{1} \frac{(\mathrm{i} \mathrm{c})^{\mathrm{k}}}{\mathrm{k}(\mathrm{ki} 1)} \pitchfork \frac{\mathrm{kz} \mathrm{i} \mathrm{c}}{(\mathrm{z} \mathrm{i} \mathrm{c})^{\mathrm{k}_{\mathrm{i}} 1}} \\
& =\sum_{\mathrm{k}=1}^{1} \frac{(\mathrm{i} \mathrm{c})^{\mathrm{k}+1}}{\mathrm{k}(\mathrm{k}+1)} \phi \frac{(\mathrm{k}+1) \mathrm{z} \mathrm{i} \mathrm{c}}{(\mathrm{zi} \mathrm{c})^{\mathrm{k}}} \\
& =\mathrm{c} \sum_{\mathrm{k}=1}^{1} \frac{(\mathrm{i} 1)^{\mathrm{k}+1}}{\mathrm{k}}\left(\frac{\mathrm{c}}{\mathrm{zi} \mathrm{c}}\right)^{\mathrm{k}} \\
& i c^{2} \sum_{k=1}^{1}(i \quad 1)^{k+1}\left(\frac{1}{k} i \frac{1}{k+1}\right)\left(\frac{c}{z i c}\right)^{k} \\
& =\mathrm{c}\left(\mathrm{z} \text { i c c) } \sum_{\mathrm{k}=1}^{1} \frac{(\mathrm{i} 1)^{\mathrm{k}+1}}{\mathrm{k}}\left(\frac{\mathrm{c}}{\mathrm{zi} \mathrm{c}}\right)^{\mathrm{k}}\right. \\
& +c(z ; \quad c) \sum_{k=1}^{1} \frac{(i 1)^{k+1}}{k+1}\left(\frac{c}{z i \quad c}\right)^{k+1} \text { : }
\end{aligned}
$$

Now, under the hypothesis (1.9) of Theorem 1, we can apply the expansion formula (1.19) to each of the infinite series in (1.25). We thus find that

$$
\begin{aligned}
\mathrm{S} & =\mathrm{c}(\mathrm{z} \text { i c })\left\{\log \left(1+\frac{\mathrm{c}}{\mathrm{zic}}\right)+\left[\frac{\mathrm{c}}{\mathrm{zic}} \mathrm{i} \log \left(1+\frac{\mathrm{c}}{\mathrm{zic}}\right)\right]\right\} \\
& =\mathrm{c}^{2} \quad\left(\mathrm{c} ; \mathrm{z} 2 \mathrm{C} ;\left|\frac{\mathrm{c}}{\mathrm{zic}}\right|<1\right)
\end{aligned}
$$

which evidently proves Theorem 1 .

Alternatively (and relatively more simply), in view of the expansion formula (1.19) and the elementary identity:

$$
k z \text { i } c=k(z \text { i } c)+(k \text { i } 1) c ;
$$

the first member $\mathrm{S}$ of the assertion (1.8) of Theorem 1 can immediately be rewritten in the form: 


$$
\begin{aligned}
& \mathrm{S}:=\sum_{\mathrm{k}=2}^{1} \frac{(\mathrm{i} \mathrm{c})^{\mathrm{k}}}{\mathrm{k}(\mathrm{ki} 1)} \pitchfork \frac{\mathrm{kz} \mathrm{i} \mathrm{c}}{(\mathrm{zi} \mathrm{c})^{\mathrm{k}_{\mathrm{i}} 1}} \\
& =\sum_{k=2}^{1} \frac{(\mathrm{i} \mathrm{c})^{k}}{k(k i 1)} \pitchfork \frac{k(z i c)+(k i 1) c}{(z i c)^{k i ~} 1} \\
& =\sum_{k=2}^{1} \frac{(\mathrm{i} \mathrm{c})^{\mathrm{k}}}{(\mathrm{ki} 1)(\mathrm{zi} \quad \mathrm{c})^{\mathrm{k}_{\mathrm{i}} 2}}+\mathrm{c} \sum_{\mathrm{k}=2}^{1} \frac{(\mathrm{i} \mathrm{c})^{\mathrm{k}}}{\mathrm{k}(\mathrm{zi} \quad \mathrm{c})^{\mathrm{k}_{\mathrm{i}} 1}} \\
& =c(z i \quad c) \sum_{k=1}^{1} \frac{(i 1)^{k+1}}{k}\left(\frac{c}{z i \quad c}\right)^{k}+c(z i \quad c) \sum_{k=1}^{1} \frac{(i 1)^{k+1}}{k+1}\left(\frac{c}{z i \quad c}\right)^{k+1}
\end{aligned}
$$

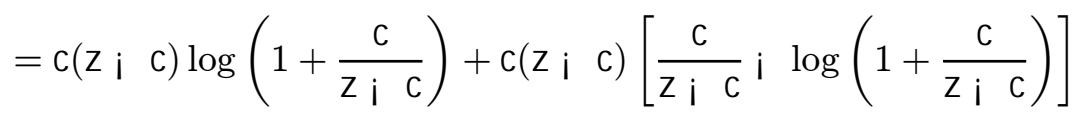

$$
\begin{aligned}
& =\mathrm{c}^{2} \quad\left(\mathrm{c} ; \mathrm{z} 2 \mathrm{C} ;\left|\frac{\mathrm{c}}{\mathrm{zi} \mathrm{C}}\right|<1\right) \text {; }
\end{aligned}
$$

which is precisely the second member of the assertion (1.8) of Theorem 1. By noticing the obvious similarity of the last two infinite series above, we remark that the use of the expansion formula (1.19) can also be avoided completely in this alternative (and relatively simpler) derivation of the assertion (1.8) of Theorem 1.

Next we turn to the alternative derivation of the assertion (1.10) of Theorem 2 without using fractional calculus. Since

$$
z=\frac{\Gamma(\mathbf{z}+1)}{\Gamma(\mathbf{z})} \quad\left(\mathrm{z} 2 \mathrm{C} ;\left|\frac{\Gamma(\mathbf{z}+1)}{\Gamma(\mathbf{z})}\right|<\mathbf{1}\right)
$$

by appealing appropriately to the definitions (1.22) and (1.23), we readily find from the left-hand side of (1.10) that

$$
\begin{aligned}
\Omega(\mathrm{a} ; \mathrm{b} ; \mathrm{c}): & =\sum_{\mathrm{k}=1}^{1} \frac{(\mathrm{k}+\mathrm{c}+\mathrm{a} \mathrm{i} 1) \Gamma\left(\mathrm{k}+\mathrm{a}+\mathrm{b}_{\mathrm{i}} 1\right)}{\mathrm{k} !}\left(\mathrm{i} \frac{\mathrm{c}}{\mathrm{b}_{\mathrm{i}} \mathrm{c}}\right)^{\mathrm{k}} \\
& =(\mathrm{c}+\mathrm{a} ; 1) \Gamma\left(\mathrm{a}+\mathrm{b}_{\mathrm{i}} 1\right)\left({ }_{2} \mathrm{~F}_{1}\left[\begin{array}{r}
\mathrm{c}+\mathrm{a} ; \mathrm{a}+\mathrm{b}_{\mathrm{i}} 1 ; \\
\mathrm{c}+\mathrm{a}_{\mathrm{i}} 1 ;
\end{array} \frac{\mathrm{c}}{\mathrm{b}_{\mathrm{i}} \mathrm{c}}\right] \mathrm{i} 1\right)
\end{aligned}
$$

in terms of the Gauss hypergeometric function which corresponds to a special case of the definition (1.22) when

$$
\mathrm{p}=2 \text { and } \mathrm{q}=1 \text { : }
$$


Upon setting

$$
\begin{aligned}
& \mathrm{p}=2 ; \mathrm{q}=1 ; \mathrm{m}=1 ;{ }_{\mathrm{R}}=\mathrm{a}+\mathrm{b}_{\mathrm{i}} 1 ;{ }^{-} \mathrm{l}=\mathrm{c}+\mathrm{a} \mathrm{i} 1 ; \text { and } \\
& \mathrm{z}=\mathrm{i} \frac{\mathrm{c}}{\mathrm{b}_{\mathrm{i}} \mathrm{c}}
\end{aligned}
$$

in the hypergeometric reduction formula (1.21), and recalling that

$$
{ }_{1} \mathrm{~F}_{0}(, ;-; \mathrm{z})=(1 \mathrm{i} \mathbf{z})^{\mathrm{i}}, \quad(, 2 \mathrm{C} ; \mathrm{jzj}<1) \text {; }
$$

we obtain

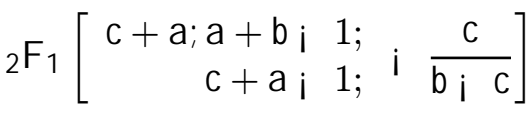

$$
\begin{aligned}
& =\sum_{j=0}^{1}\left(\begin{array}{l}
1 \\
j
\end{array}\right) \frac{\left(a+b_{i} 1\right)_{j}}{\left(c+a_{i} 1\right)_{j}}\left(i \frac{c}{b_{i} c}\right)^{j} \phi\left(1+\frac{c}{b_{i} c}\right)^{1_{i} a_{i} b_{i} j} \\
& =\left(\frac{b}{b_{i} c}\right)^{l_{i} a_{i} b} i \frac{a+b_{i} 1}{c+a i 1} \phi \frac{c}{b_{i} c}\left(\frac{b}{b_{i} c}\right)^{i a_{i} b} \\
& =\left(\frac{b_{i} c}{b}\right)^{a+b}\left(\frac{b}{b_{i} c} i \frac{c(a+b i 1)}{(c+a i 1)\left(b_{i} c\right)}\right) \\
& =\frac{a_{i} 1}{c+a i 1}\left(\frac{b_{i} c}{b}\right)^{a+b} \text {; }
\end{aligned}
$$

which holds true under the constraints (1.11) and (1.12), exceptional parameter values (that would render any expression invalid or undefined) being tacitly excluded.

The assertion (1.10) of Theorem 2 would now follow immediately upon substituting from (1.30) into the last member of (1.27).

For the sake of ready reference, we choose also to state the aforementioned generalizations of Theorem 1 and Theorem 2, given by Salinas de Romero and Srivastava [14, p. 142, Equations (3.2) and (3.3)], as follows:

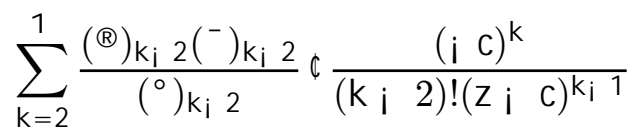

$$
\begin{aligned}
& \Phi\left[\mathrm{zi} \quad \mathrm{c}\left(1 \mathrm{i} \frac{(\circledR+\mathrm{k} \text { i } 2)\left({ }^{-}+\mathrm{k} \text { i } 2\right)}{(\mathrm{k} \text { i } 1)\left({ }^{\circ}+\mathrm{k} \text { i } 2\right)}\right)\right]=\mathrm{c}^{2} \\
& \left(\circ z Z_{0}^{i} ;\left|\frac{c}{z_{i} C}\right|<1 ; c ; z 2 c\right)
\end{aligned}
$$


or, more generally,

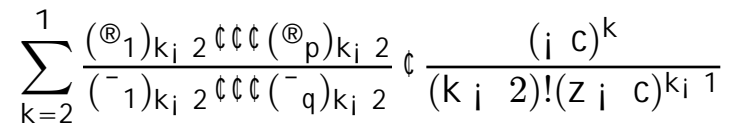

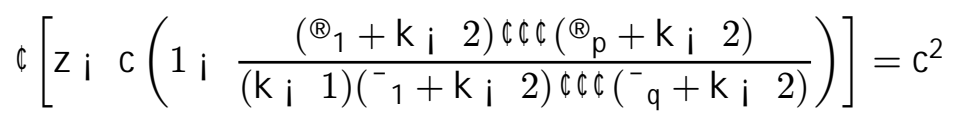

$$
\begin{aligned}
& \left(\mathrm{p} \leqq \mathrm{q} ; \mathrm{p}=\mathrm{q}+1 \quad \text { and } \quad\left|\frac{\mathrm{c}}{\mathrm{zi} \mathrm{c}}\right|<1 ; \mathrm{c} ; \mathrm{z} 2 \mathrm{C}\right)
\end{aligned}
$$

provided that each member of (1.31) and (1.32) exists.

Remark 1. The summation formula (1.31) corresponds to a special case of (1.32) when

$$
\mathrm{p}=2 ; \mathrm{q}=1 ; \mathbb{R}_{1}={ }^{\circledR}, \mathbb{R}_{2}={ }^{-} ; \text {and }{ }^{-}{ }_{1}={ }^{\circ}:
$$

Furthermore, in its special case when

$$
\circledR=^{-}=1 \quad \text { and } \quad{ }^{\circ}=2 ;
$$

(1.31) would yield the assertion (1.8) of Theorem 1.

$$
\begin{gathered}
\sum_{k=2}^{1} \frac{(\mathrm{i} \mathrm{c})^{k}}{\left(k+m_{i} 1\right)\left(k+m_{i} 2\right)} \pitchfork \frac{\left(k+m_{i} 1\right) z i c}{(z i c)^{k i} 1}=\frac{c^{2}}{m} \\
\left(m 2 N ;\left|\frac{c}{z i c}\right|<1 ; c ; z 2 c\right)
\end{gathered}
$$

or, slightly more generally,

$$
\begin{aligned}
& \sum_{k=2}^{1} \frac{(\mathrm{i} \mathrm{c})^{k}}{\left(k+\mathrm{l}_{\mathrm{i}} 1\right)\left(\mathrm{k}+\mathrm{m}_{\mathrm{i}} 1\right)} \pitchfork \frac{\left(\mathrm{k}+\mathrm{m}_{\mathrm{i}} 1\right) \mathrm{zi}\left(\mathrm{m}_{\mathrm{i}} \mathrm{l}\right) \mathrm{c}}{(\mathrm{zi} \mathrm{c})^{\mathrm{k}_{\mathrm{i}} 1}} \\
& =c^{2}\left[\left(1 ; \frac{z}{c}\right)^{l+1} i\left(1 ; \frac{z}{c}\right)^{m}\right] \log \left(1 ; \frac{z}{c}\right) \\
& +c(z i \quad c) \sum_{k=0}^{l_{i} 1} \frac{f c=(c i \quad z) g^{k_{i} l+1}}{k+1} \\
& +c^{2} \sum_{k=0}^{m_{i}{ }^{1}} \frac{f c=\left(c_{i} \quad z\right) g^{k i m+1}}{k+1} \\
& \left(\text { I } 2 \mathrm{~N}_{0} ; \mathrm{m} 2 \mathrm{~N} ;\left|\frac{\mathrm{C}}{\mathrm{zi} \mathrm{C}}\right|<1 ; \mathrm{c} ; \mathrm{z} 2 \mathrm{C}\right) \text {; }
\end{aligned}
$$


where exceptional values of $\mathrm{C}$ and $\mathrm{z}$ (which would render either side of (1.34) invalid or undefined) are tacitly excluded.

Remark 2. In its special case when

$$
\mathrm{I}=\mathrm{m}_{\mathrm{i}} 1 \quad(\mathrm{~m} 2 \mathrm{~N})
$$

the summation formula (1.34) would reduce at once to (1.27) which, in turn, yields the assertion (1.8) of Theorem 1 when we further set $\mathrm{m}=1$ :

The following consequence of the hypergeometric reduction formula (1.21) does provide a generalization of Theorem 2, which was also given by Salinas de Romero and Srivastava [14, p. 144, Equation (3.9)]:

$$
\begin{aligned}
& \sum_{\mathrm{k}=1}^{1}\left(\mathrm{k}+{ }^{-}\right) \mathrm{m} \Gamma(\mathrm{k}+\AA) \frac{\mathrm{z}^{\mathrm{k}}}{\mathrm{k} !} \\
& =\Gamma(\circledast)\left\{\sum_{j=0}^{m}\left(\begin{array}{c}
m \\
j
\end{array}\right) \frac{\left.\left({ }^{\circledR}\right) j^{-}\right) m}{\left(^{-}\right) j} \frac{z^{j}}{(1 ; \quad z)^{\circledR+j}} i \quad\left(^{-}\right)_{m}\right\} \\
& \left({ }^{\circledR} 2 \mathrm{C} ; \quad-2 \mathrm{C} \text { n } \mathrm{Z}_{0}^{i} ; \mathrm{jzj}<1\right) \text { : }
\end{aligned}
$$

Remark 3. In its special case when

$$
\mathrm{m}=1 ; \AA=a+b_{i} 1 ;-=c+a i 1 ; \quad \text { and } \quad \mathrm{z}=\mathrm{i} \frac{\mathrm{c}}{\mathrm{b}_{\mathrm{i}} \mathrm{c}} ;
$$

the summation formula (1.35) would immediately yield the assertion (1.10) of Theorem 2 .

Yet another interesting generalization of Theorem 1, which does not seem to follow easily from any of the generalizations (1.31) to (1.34) of Theorem 1 due to Salinas de Romero and Srivastava [14], was presented recently by Nishimoto et al. [10]. We recall here the main result of Nishimoto et al. [10] as

Theorem 3 (cf . Nishimoto et al. [10]). Let $\mathrm{H}_{\mathrm{n}}$ denote the familiar harmonic numbers defined by

$$
\mathrm{H}_{\mathrm{n}}:= \begin{cases}\sum_{\mathrm{k}=1}^{\mathrm{n}} \frac{1}{\mathrm{k}} & (\mathrm{n} 2 \mathrm{~N}) \\ 0 & \left(\mathrm{n} 2 \mathrm{Z}_{0}^{\mathrm{i}}\right):\end{cases}
$$


Then

$$
\begin{aligned}
& \sum_{k=n+1}^{1} \frac{\Gamma(k i n)}{k !}\left(i \frac{c}{z i c}\right)^{k}
\end{aligned}
$$

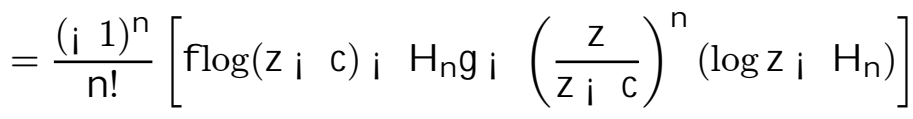

$$
\begin{aligned}
& +\sum_{k=1}^{n} \frac{(i 1)^{n}}{k !(n i k) !}\left(\frac{c}{z i c}\right)^{k} f \log (z i c) i H_{n_{i} k g} \\
& \left(\mathrm{n} 2 \mathrm{~N}_{0} ;\left|\frac{\mathrm{C}}{\mathrm{zi} \mathrm{C}}\right|<1 ; \mathrm{c} ; \mathrm{z} 2 \mathrm{C}\right) \text {; }
\end{aligned}
$$

provided that each member of the assertion (1.37) exists.

In view of the definition (1.36), upon setting $\mathrm{n}=1$ in the assertion (1.37) of Theorem 3, we obtain

$$
\begin{aligned}
& \sum_{k=2}^{1} \frac{(\mathrm{i} \mathrm{c})^{k}}{k(k i 1)} \pitchfork \frac{1}{(z i c)^{k i 1}}=z \log \left(\frac{z}{z i c}\right) i c \\
& \left(\left|\frac{\mathrm{C}}{\mathrm{zi} C}\right|<1 ; \mathrm{c} ; \mathrm{z} 2 \mathrm{C}\right) \text {; }
\end{aligned}
$$

so that, by appealing also to the expansion formula (1.20) with $\mathrm{m}=1$, we find that

$$
\begin{aligned}
& \sum_{k=2}^{1} \frac{(\mathrm{i} \mathrm{c})^{\mathrm{k}}}{\mathrm{k}(\mathrm{ki} 1)} \pitchfork \frac{\mathrm{kz} \mathrm{i} \mathrm{c}}{(\mathrm{zi} \mathrm{c})^{\mathrm{k} i ~} 1} \\
& =\mathrm{i} \quad \mathrm{z} \sum_{\mathrm{k}=0}^{1} \frac{(\mathrm{i} 1)^{\mathrm{k}+1}}{\mathrm{k}+1}\left(\frac{\mathrm{c}}{\mathrm{zi} \mathrm{c}}\right)^{\mathrm{k}+1} \mathrm{i} \mathrm{c}\left[\mathrm{z} \log \left(\frac{\mathrm{z}}{\mathrm{zi} \mathrm{c}}\right) \mathrm{i} \quad \mathrm{c}\right] \\
& =\mathrm{i} c\left[\mathrm{i} \log \left(1+\frac{\mathrm{c}}{\mathrm{zic}}\right)\right] \mathrm{i} \mathrm{c}\left[\mathrm{z} \log \left(\frac{\mathrm{z}}{\mathrm{zic}}\right) \mathrm{i} \mathrm{c}\right] \\
& =\mathrm{c}^{2} \quad\left(\left|\frac{\mathrm{c}}{\mathrm{zi} \mathrm{C}}\right|<1 ; \mathrm{c} ; \mathrm{z} 2 \mathrm{2} \mathrm{C}\right) \text {; }
\end{aligned}
$$

which is precisely the assertion (1.8) of Theorem 1.

In their proof of Theorem 3, Nishimoto et al. [10] apply many of the aforementioned lemmas and properties involving the fractional differintegral of logarithm and power functions as well as the generalized Leibniz rule for the differintegral 
of the product of two functions, and indeed also the following exceptional case of Property 3 above:

$$
\left(\log \left(\begin{array}{ll}
z & c
\end{array}\right)\right)_{i} n=\frac{(z i \quad c)^{n}}{n !} f \log \left(\begin{array}{lll}
z & c
\end{array}\right) \text { i } H_{n} g
$$

\section{(c; 22 C; n 2 No);}

where we have continued to use the differintegral notation of (1.18) with $\stackrel{\mathrm{o}}{=} \mathrm{i} \mathrm{n}$ ( $\mathrm{n} 2 \mathrm{~N}_{0}$ ) and $\mathrm{H}_{\mathrm{n}}$ denotes the harmonic numbers defined by (1.36). Our main object in the present sequel to the work of Nishimoto et al. [10] is to demonstrate that, not only the assertion (1.37) of Theorem 3, but substantially more general families of infinite sums can also be evaluated without using the fractional differintegral operator defined by (1.3).

\section{Derivations Without Using Operators of Fractional Calculus}

At the outset, if we denote the left-hand side of the assertion (1.37) of Theorem 3 by $\Omega_{\mathrm{n}}(\mathrm{c} ; \mathrm{z})$, we find from the definition (1.23) that

$$
\begin{aligned}
& \Omega_{\mathrm{n}}(\mathrm{c} ; \mathrm{z}):=\sum_{\mathrm{k}=\mathrm{n}+1}^{1} \frac{\Gamma(\mathrm{k} \mathrm{i} n)}{\mathrm{k} !}\left(\mathrm{i} \frac{\mathrm{c}}{\mathrm{zi} \mathrm{c}}\right)^{\mathrm{k}} \\
& =\sum_{k=2}^{1} \frac{\Gamma(k i 1)}{(k+n i 1) !}\left(i \frac{c}{z_{i} c}\right)^{k+n_{i} 1}
\end{aligned}
$$

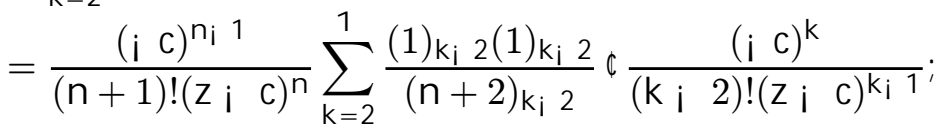

which exhibits the fact that the infinite sum in the assertion (1.37) of Theorem 3 is essentially analogous to the series involved in the summation formula (1.31) with, of course,

$$
\circledR{ }^{-}=1 \quad \text { and } \quad{ }^{\circ}=\mathrm{n}+2 \quad(\mathrm{n} 2 \mathrm{~N}) \text { : }
$$

Moreover, in terms of the Gauss hypergeometric ${ }_{2} \mathrm{~F}_{1}$ function which, just as we remarked above in connection with (1.27), corresponds to a special case of the generalized hypergeometric ${ }_{p} F_{q}$ function defined by (1.22) when

$$
\text { pi } 1=q=1 \text {; }
$$

it immediately follows from (2.1) that

$$
\Omega_{\mathrm{n}}(\mathrm{c} ; \mathrm{z})=\frac{\mathrm{fc}=(\mathrm{C} ; \mathrm{z}) \mathrm{g}^{\mathrm{n}+1}}{(\mathrm{n}+1) !}{ }_{2} \mathrm{~F}_{1}\left(1 ; 1 ; \mathrm{n}+2 ; \mathrm{i} \frac{\mathrm{c}}{\mathrm{zi} \mathrm{c}}\right)
$$




$$
\left(\mathrm{n} 2 \mathrm{~N}_{0} ;\left|\frac{\mathrm{C}}{\mathrm{zi} \mathrm{C}}\right|<1 ; \mathrm{c} ; \mathrm{z} 2 \mathrm{C}\right) \text { : }
$$

Thus, upon simplifying the right-hand side of (1.37), if we compare (1.37) and (2.2), we can rewrite the assertion (1.37) of Theorem 3 in its equivalent form:

$$
\begin{aligned}
{ }_{2} \mathrm{~F}_{1}\left(1 ; 1 ; \mathrm{n}+2 ; \mathrm{i} \frac{\mathrm{c}}{\mathrm{zi} \mathrm{c}}\right) \\
=(\mathrm{n}+1)\left[\left(1 ; \frac{\mathrm{z}}{\mathrm{c}}\right)\left(\frac{\mathrm{z}}{\mathrm{c}}\right)^{\mathrm{n}}\left\{\mathrm{H}_{\mathrm{n}} \mathrm{i} \log \left(\frac{\mathrm{z}}{\mathrm{zic}}\right)\right\}\right. \\
\left.+\sum_{\mathrm{k}=0}^{\mathrm{n}}\left(\begin{array}{l}
\mathrm{n} \\
\mathrm{k}
\end{array}\right)\left(\frac{\mathrm{c}}{\mathrm{zic}}\right)^{\mathrm{k}_{\mathrm{i}} \mathrm{n}_{\mathrm{i}} 1} \mathrm{H}_{\mathrm{n}_{\mathrm{i}} \mathrm{k}}\right] \\
\quad\left(\mathrm{n} 2 \mathrm{~N}_{0} ;\left|\frac{\mathrm{c}}{\mathrm{zi} \mathrm{C}}\right|<1 ; \mathrm{c} ; \mathrm{z} 2 \mathrm{C}\right):
\end{aligned}
$$

Since

$$
\left(\frac{z}{c}\right)^{n}=\left(1+\frac{z i c}{c}\right)^{n}=\sum_{k=0}^{n}\left(\begin{array}{l}
n \\
k
\end{array}\right)\left(\frac{z i c}{c}\right)^{k}
$$

and

$$
\left(1 \text { i } \frac{z}{c}\right)\left(\frac{z}{c}\right)^{n}=i \sum_{k=0}^{n}\left(\begin{array}{l}
n \\
k
\end{array}\right)\left(\frac{z i c}{c}\right)^{k+1} ;
$$

the assertion (1.37) of Theorem 3 can also be put in the elegant form:

$$
\begin{aligned}
{ }_{2} \mathrm{~F}_{1}\left(1 ; 1 ; \mathrm{n}+2 ; \mathrm{i} \frac{\mathrm{c}}{\mathrm{zi} \mathrm{C}}\right) \\
=(\mathrm{n}+1) \sum_{\mathrm{k}=0}^{\mathrm{n}}\left(\begin{array}{l}
\mathrm{n} \\
\mathrm{k}
\end{array}\right)\left(\frac{\mathrm{zic}}{\mathrm{c}}\right)^{\mathrm{k}+1}\left\{\log \left(\frac{\mathrm{z}}{\mathrm{zic}}\right) \mathrm{i}\left(\mathrm{H}_{\mathrm{n} \mathrm{i}} \mathrm{H}_{\mathrm{k}}\right)\right\} \\
\left(\mathrm{n} 2 \mathrm{~N}_{0} ;\left|\frac{\mathrm{c}}{\mathrm{zi} \mathrm{C}}\right|<1 ; \mathrm{c} ; \mathrm{z} 2 \mathrm{C}\right):
\end{aligned}
$$

The case $\mathrm{n}=0$ of the equivalent summation formulas (1.37), (2.3), and (2.6) corresponds to the well-known relationship [1, p. 102, Equation 2.8 (15)]:

$$
{ }_{2} \mathrm{~F}_{1}(1 ; 1 ; 2 ; \mathrm{z})=\mathrm{i} \frac{1}{\mathrm{z}} \log (1 ; \mathrm{z}) ;
$$

which would follow immediately when we compare (1.19) and the definition (1.22) with, of course,

$$
\mathrm{p}_{\mathrm{i}} 1=\mathrm{q}=1 \quad \text { and } \quad \mathbb{R}_{1}={ }^{-}{ }_{1}={ }^{\circ} \text { i } 1=1:
$$


Also, starting from the relationship (2.7) and applying the known recurrence (or, more precisely, contiguous-function) relation [1, p. 103, Equation 2.8 (38)]:

$$
\begin{gathered}
{ }^{\circ}(1 \mathrm{i} \quad \mathrm{z}){ }_{2} \mathrm{~F}_{1}\left(\AA_{1}{ }^{-} ;{ }^{\circ} ; \mathrm{z}\right) \mathrm{i}^{\circ}{ }_{2} \mathrm{~F}_{1}\left({ }^{\circledR} \mathrm{i} 1 ;^{-} ;{ }^{\circ} ; \mathrm{z}\right) \\
+\left({ }^{\circ} \mathrm{i}^{-}\right) \mathrm{z}_{2} \mathrm{~F}_{1}\left({ }^{\circledR}{ }^{-} ;{ }^{\circ}+1 ; \mathrm{z}\right)=0 ;
\end{gathered}
$$

which, upon setting ${ }^{\circledR}={ }^{-}=1$; assumes the remarkably simple form:

$$
{ }_{2} \mathrm{~F}_{1}\left(1 ; 1 ;^{\circ}+1 ; \mathrm{z}\right)=\frac{{ }^{\circ}}{\left({ }^{\circ} \mathbf{i} 1\right) \mathrm{z}}\left[1 \mathrm{i} \quad(1 \mathrm{i} \quad \mathrm{z}){ }_{2} \mathrm{~F}_{1}\left(1 ; 1 ;{ }^{\circ} ; \mathrm{z}\right)\right] \quad\left({ }^{\circ} \text { G } 1\right) ;
$$

we obtain

$$
{ }_{2} \mathrm{~F}_{1}(1 ; 1 ; 3 ; \mathbf{z})=\frac{2}{\mathbf{z}}\left[1 \mathbf{i}\left(\frac{\mathbf{z} \mathbf{i} 1}{\mathbf{z}}\right) \log (1 ; \mathbf{z})\right]
$$

which corresponds to the case $\mathrm{n}=1$ of the equivalent summation formulas (1.37), (2.3), and (2.6).

By making use of the recurrence relation (2.9) with

$$
{ }^{\circ}=\mathrm{n}+2 \quad \text { and } \quad \mathrm{z} \nabla ! \mathrm{i} \frac{\mathrm{C}}{\mathrm{zi} \mathrm{C}} ;
$$

it is not difficult to prove the general summation formula (2.6), and hence also its equivalent forms (1.37) and (2.3), by appealing to the principle of mathematical induction for every nonnegative integer $n$. Indeed, if we assume that the summation formula (2.6) holds true for some positive integer $n$, we thus find from (2.9) and (2.6) that

$$
\begin{aligned}
& { }_{2} \mathrm{~F}_{1}\left(1 ; 1 ; \mathrm{n}+3 ; \mathrm{i} \frac{\mathrm{c}}{\mathrm{zic}}\right) \\
& =\mathrm{i} \frac{\mathrm{n}+2}{\mathrm{n}+1}\left(\frac{\mathrm{zic}}{\mathrm{c}}\right)\left[1 \mathrm{i}\left(1+\frac{\mathrm{c}}{\mathrm{zic}}\right){ }_{2} \mathrm{~F}_{1}\left(1 ; 1 ; \mathrm{n}+2 ; \mathrm{i} \frac{\mathrm{c}}{\mathrm{zic}}\right)\right] \\
& =\mathrm{i} \frac{\mathrm{n}+2}{\mathrm{n}+1}\left(\frac{\mathrm{zic}}{\mathrm{c}}\right)+\frac{\mathrm{n}+2}{\mathrm{n}+1}\left(1+\frac{\mathrm{zic}}{\mathrm{c}}\right){ }_{2} \mathrm{~F}_{1}\left(1 ; 1 ; \mathrm{n}+2 ; \mathrm{i} \frac{\mathrm{c}}{\mathrm{zi} \mathrm{c}}\right) \\
& =\mathrm{i} \frac{\mathrm{n}+2}{\mathrm{n}+1}\left(\frac{\mathrm{zi} \mathrm{c}}{\mathrm{c}}\right)+(\mathrm{n}+2)\left[\sum_{\mathrm{k}=0}^{\mathrm{n}}\left(\begin{array}{l}
\mathrm{n} \\
\mathrm{k}
\end{array}\right)\left(\frac{\mathrm{zi} \mathrm{c}}{\mathrm{c}}\right)^{\mathrm{k}+1}\right. \\
& \Phi\left\{\log \left(\frac{\mathrm{z}}{\mathrm{z} \mathbf{i} \mathrm{C}}\right) \text { i }\left(\mathrm{H}_{\mathrm{n}} \mathrm{i} \mathrm{H}_{\mathrm{k}}\right)\right\} \\
& \left.+\sum_{\mathrm{k}=0}^{\mathrm{n}}\left(\begin{array}{l}
\mathrm{n} \\
\mathrm{k}
\end{array}\right)\left(\frac{\mathrm{z} \mathrm{i} \mathrm{c}}{\mathrm{c}}\right)^{\mathrm{k}+2}\left\{\log \left(\frac{\mathrm{z}}{\mathrm{zi} \mathrm{c}}\right) \mathrm{i}\left(\mathrm{H}_{\mathrm{n}} \mathrm{i} \mathrm{H}_{\mathrm{k}}\right)\right\}\right]
\end{aligned}
$$




$$
\begin{aligned}
= & i \frac{n+2}{n+1}\left(\frac{z i c}{c}\right)+(n+2)\left[\sum_{k=0}^{n}\left(\begin{array}{l}
n \\
k
\end{array}\right)\left(\frac{z i c}{c}\right)^{k+1}\right. \\
& \$\left\{\log \left(\frac{z}{z i c}\right) i\left(H_{n} i H_{k}\right)\right\} \\
& \left.+\sum_{k=1}^{n+1}\left(\begin{array}{cc}
n \\
k i & 1
\end{array}\right)\left(\frac{z i c}{c}\right)^{k+1}\left\{\log \left(\frac{z}{z i c}\right) i\left(H_{n} i H_{k i} 1\right)\right\}\right] \\
= & i \frac{n+2}{n+1}\left(\frac{z i c}{c}\right)+(n+2)\left[\sum_{k=0}^{n+1}\left(\begin{array}{c}
n+1 \\
k
\end{array}\right)\left(\frac{z i c}{c}\right)^{k+1}\right. \\
& \left.\$\left\{\log \left(\frac{z}{z i c}\right) i\left(H_{n} i H_{k}\right)\right\} i \sum_{k=1}^{n+1} \frac{1}{k}\left(\begin{array}{cc}
n \\
k i
\end{array}\right)\left(\frac{z i c}{c}\right)^{k+1}\right] ;
\end{aligned}
$$

where we have made use of the combinatorial identity:

$$
\left(\begin{array}{l}
\jmath \\
k
\end{array}\right)+\left(\begin{array}{cc}
s \\
k i & 1
\end{array}\right)=\left(\begin{array}{c}
++1 \\
k
\end{array}\right) \quad(k 2 N ;, 2 C)
$$

and the fact that

$$
\mathrm{H}_{\mathrm{k}_{\mathrm{i}} 1}=\mathrm{H}_{\mathrm{k}} \mathrm{i} \frac{1}{\mathrm{k}} \quad(\mathrm{k} 2 \mathrm{~N}) \text { : }
$$

Applying (2.13) once again with $\mathrm{k}=\mathrm{n}+1\left(\mathrm{n} 2 \mathrm{~N}_{0}\right)$, (2.11) immediately yields

$$
\begin{aligned}
& { }_{2} \mathrm{~F}_{1}\left(1 ; 1 ; \mathrm{n}+3 ; \mathrm{i} \frac{\mathrm{c}}{\mathrm{z} \mathbf{~ c ~}}\right) \\
& =i \frac{n+2}{n+1}\left(\frac{z i c}{c}\right)+(n+2)\left[\sum_{k=0}^{n+1}\left(\begin{array}{c}
n+1 \\
k
\end{array}\right)\left(\frac{z i c}{c}\right)^{k+1}\right. \\
& \Phi\left\{\log \left(\frac{\mathrm{z}}{\mathrm{zi} \mathrm{c}}\right) \mathrm{i}\left(\mathrm{H}_{\mathrm{n}+1} \mathrm{i} \mathrm{H}_{\mathrm{k}}\right)\right\}+\frac{1}{\mathrm{n}+1} \sum_{\mathrm{k}=0}^{\mathrm{n}+1}\left(\begin{array}{c}
\mathrm{n}+1 \\
\mathrm{k}
\end{array}\right)\left(\frac{\mathrm{zic}}{\mathrm{c}}\right)^{\mathrm{k}+1} \\
& \left.\mathrm{i} \sum_{\mathrm{k}=1}^{\mathrm{n}+1} \frac{1}{\mathrm{k}}\left(\begin{array}{c}
\mathrm{n} \\
\mathrm{k} i \mathrm{i}
\end{array}\right)\left(\frac{\mathrm{z} \mathrm{i} c}{\mathrm{c}}\right)^{\mathrm{k}+1}\right] \\
& =i \frac{n+2}{n+1}\left(\frac{z i c}{c}\right)+(n+2)\left[\sum_{k=0}^{n+1}\left(\begin{array}{c}
n+1 \\
k
\end{array}\right)\left(\frac{z i c}{c}\right)^{k+1}\right. \\
& \Phi\left\{\log \left(\frac{\mathrm{z}}{\mathrm{zi} \mathrm{C}}\right) \mathrm{i}\left(\mathrm{H}_{\mathrm{n}+1} \mathrm{i} \mathrm{H}_{\mathrm{k}}\right)\right\}+\frac{1}{\mathrm{n}+1}\left(\frac{\mathrm{zic}}{\mathrm{c}}\right)
\end{aligned}
$$

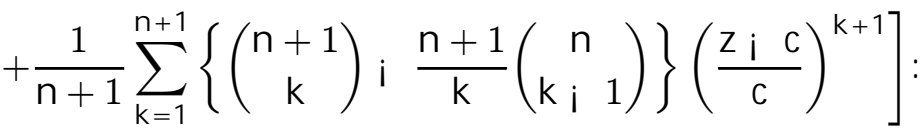


Since

$$
\left(\begin{array}{c}
++1 \\
k
\end{array}\right)=\frac{,+1}{k}\left(\begin{array}{cc}
, \\
k i & 1
\end{array}\right) \quad(k 2 N ;, 2 \mathrm{C})
$$

it follows from (2.14) that

$$
\begin{aligned}
{ }_{2} \mathrm{~F}_{1}\left(1 ; 1 ; \mathrm{n}+3 ; \mathrm{i} \frac{\mathrm{c}}{\mathrm{zic}}\right) & (\mathrm{n}+2) \sum_{\mathrm{k}=0}^{\mathrm{n}+1}\left(\begin{array}{c}
\mathrm{n}+1 \\
\mathrm{k}
\end{array}\right)\left(\frac{\mathrm{zic}}{\mathrm{c}}\right)^{\mathrm{k}+1}\left\{\log \left(\frac{\mathrm{z}}{\mathrm{zic}}\right) \mathrm{c}\left(\mathrm{H}_{\mathrm{n}+1} \mathrm{i} \mathrm{H}_{\mathrm{k}}\right)\right\} \\
& \left(\mathrm{n} 2 \mathrm{~N}_{0} ;\left|\frac{\mathrm{c}}{\mathrm{zi} \mathrm{c}}\right|<1 ; \mathrm{c} ; \mathrm{z} 2 \mathrm{C}\right) ;
\end{aligned}
$$

which is precisely the summation formula (2.6) with $\mathrm{n}$ replaced by $\mathrm{n}+1$ ( $\mathrm{n} 2 \mathrm{~N}_{0}$ ).

This evidently completes our proof of the summation formula (2.6), and hence also of its equivalent forms (1.37) and (2.3), by the principle of mathematical induction.

\section{Further Summation Formulas}

In view of the relationships (2.7) and (2.10), it is fairly straightforward to apply the recurrence relation (2.9) once again in order to prove (also by appealing to the principle of mathematical induction) that

$$
{ }_{2} \mathrm{~F}_{1}(1 ; 1 ; \mathrm{n}+2 ; \mathbf{z})=\frac{\mathrm{n}+1}{\mathrm{z}}\left[\sum_{\mathrm{k}=1}^{\mathrm{n}} \frac{\mathrm{f}(\mathbf{z} \mathbf{i} 1) \Rightarrow \mathrm{g}^{\mathrm{k} i} \mathbf{1}}{\mathrm{n} \mathbf{i}+1} \mathrm{i}\left(\frac{\mathrm{z} \mathbf{i} 1}{\mathrm{z}}\right)^{\mathrm{n}} \log (1 ; \mathrm{z})\right]
$$

$$
\text { (n } \left.2 \mathrm{~N}_{0} ; 0<\mathrm{jzj}<1\right) \text {; }
$$

which immediately yields the special cases (2.7) and (2.10) when we set $\mathrm{n}=0$ and $\mathrm{n}=1$; respectively. More generally, if we similarly apply the recurrence relation (2.8) with ${ }^{-}=1$ :

$$
\begin{aligned}
{ }_{2} \mathrm{~F}_{1}\left({ }_{1}, 1 ;^{\circ}+1 ; \mathrm{z}\right)= & \frac{{ }^{\circ}}{\left({ }^{\circ} \mathrm{i} 1\right) \mathrm{z}}\left[{ }_{2} \mathrm{~F}_{1}\left({ }^{\circledR} \mathrm{i} 1 ; 1 ;{ }^{\circ} ; \mathrm{z}\right)\right. \\
& \left.\mathrm{i}(1 \mathrm{i} \mathrm{z}){ }_{2} \mathrm{~F}_{1}\left({ }_{(}, 1 ;{ }^{\circ} ; \mathrm{z}\right)\right] ;
\end{aligned}
$$


we shall obtain ( $c f .[13$, p. 462, Entry 7.3.1.128])

$$
\begin{aligned}
& { }_{2} \mathrm{~F}_{1}(\mathrm{I} ; 1 ; \mathrm{n}+2 ; \mathrm{z}) \\
& =\frac{(n+1) !}{(n i l+1) ! z}\left[\sum_{k=1}^{n_{i} I+1} \frac{\left(n_{i} k_{i} I+1\right) !}{\left(n_{i} k+1\right) !}\left(\frac{z_{i} 1}{z}\right)^{k_{i} 1}\right. \\
& \left.i \frac{z}{(1 ; 1) !}\left(\frac{z i 1}{z}\right)^{n_{i} l+1}\left\{\sum_{k=1}^{l_{i} 1} \frac{z^{i k}}{1 i k}+z^{i}{ }^{l} \log (1 ; \quad z)\right\}\right] \\
& \text { ( } 2 \mathrm{~N} ; \mathrm{n} 2 \mathrm{~N}_{0} ; \mathrm{n} \geqq \mathrm{I} \text { i } 1 ; 0<\mathrm{jzj}<1 \text { ); }
\end{aligned}
$$

which, in the special case when $I=1$; reduces at once to the relationship (3.1).

Upon substituting from (3.1) into the right-hand side of (2.2), we are easily led to the following yet another equivalent form of each of the summation formulas (1.37), (2.3), and (2.6):

$$
\begin{aligned}
\sum_{k=n+1}^{1} \frac{\Gamma(k i n)}{k !}\left(i \frac{c}{z i c}\right)^{k} & \frac{f c=(c i \quad z) g^{n}}{n !}\left[\sum_{k=1}^{n} \frac{(z=c)^{k i 1}}{n i k+1} i\left(\frac{z}{c}\right)^{n} \log \left(\frac{z}{z i c}\right)\right] \\
& \left(n 2 N_{0} ;\left|\frac{c}{z i c}\right|<1 ; c ; z 2 c\right)
\end{aligned}
$$

that is,

$$
\begin{aligned}
& { }_{2} \mathrm{~F}_{1}\left(1 ; 1 ; \mathrm{n}+2 ; \mathrm{i} \frac{\mathrm{c}}{\mathrm{zi} \mathrm{c}}\right) \\
& =(\mathrm{n}+1)\left(1 \mathrm{i} \frac{\mathrm{z}}{\mathrm{c}}\right)\left[\sum_{\mathrm{k}=1}^{\mathrm{n}} \frac{(\mathrm{z}=\mathrm{c})^{\mathrm{k}_{\mathrm{i}} 1}}{\mathrm{n} \mathrm{i}+1} \mathrm{i}\left(\frac{\mathrm{z}}{\mathrm{c}}\right)^{\mathrm{n}} \log \left(\frac{\mathrm{z}}{\mathrm{zi} \mathrm{c}}\right)\right] \\
& \left(\mathrm{n} 2 \mathrm{~N}_{0} ;\left|\frac{\mathrm{C}}{\mathrm{zi} \mathrm{c}}\right|<1 ; \mathrm{c} ; \mathrm{z} 2 \mathrm{C}\right):
\end{aligned}
$$

In case we similarly apply (3.3) instead, we shall obtain the following interesting generalization of the assertion (1.37) of Theorem 3:

$$
\begin{aligned}
& \sum_{k=n+1}^{1} \frac{\Gamma(k+l i n i 1)}{k !}\left(i \frac{c}{z i c}\right)^{k}
\end{aligned}
$$

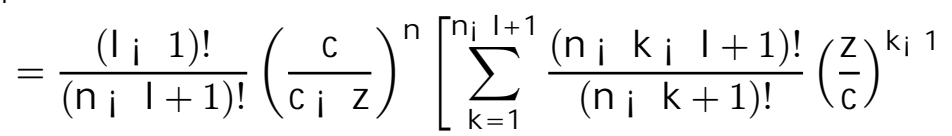

$$
\begin{aligned}
& \left.i \frac{(z=c)^{n_{i} l+1}}{(I i 1) !}\left\{\sum_{k=1}^{l_{i} 1} \frac{f 1 i(z=c) g^{k_{i} 1}}{l_{i} k}+\left(1 ; \frac{z}{c}\right)^{l_{i} 1} \log \left(\frac{z}{z i c}\right)\right\}\right]
\end{aligned}
$$




$$
\left(\text { I } 2 \mathrm{~N} ; \mathrm{n} 2 \mathrm{~N}_{0} ; \mathrm{n} \geqq \mathrm{I} \text { i } 1 ;\left|\frac{\mathrm{C}}{\mathrm{zi} \mathrm{C}}\right|<1 ; \mathrm{c} ; \mathrm{z} 2 \mathrm{C}\right) \text {; }
$$

where it is understood, as usual, that exceptional values of $C$ and $z$ (which would render any expression invalid or undefined) are tacitly excluded.

Obviously, in its special case when $I=1$; (3.6) would reduce immediately to Theorem 3 in its equivalent form (3.4).

With a view to demonstrating that the right-hand side of (3.4) is the same as that of the assertion (1.37) of Theorem 3, we recall the known sum (cf., e:g., [2, p. 363, Entry (55.7.4)]):

$$
\begin{aligned}
\sum_{\mathrm{k}=0}^{1} \frac{(,)_{\mathrm{k}}}{\mathrm{k} !} \mathrm{H}_{\mathrm{k}} \mathrm{z}^{\mathrm{k}}= & \frac{1}{1 \mathrm{i} \mathrm{z}} \Phi\left(\frac{1}{1 \mathrm{i} \mathrm{z}} ; 1 ; 1 \mathrm{i},\right) \\
& +(1 \mathrm{i} \mathrm{z}) \mathrm{i},\left[\tilde{\mathrm{A}}(1 \mathrm{i},) \mathrm{i} \tilde{\mathrm{A}}(1) \mathrm{i} \log \left(\frac{\mathrm{zi}}{\mathrm{z}}\right)\right] \\
& (, 2 \mathrm{C} \mathrm{n} \mathrm{N} ; \mathrm{jzj}<1) ;
\end{aligned}
$$

where $\Phi(z ; s ; a)$ denotes the Hurwitz-Lerch Zeta function defined by ( $c f .[1$, p. 27, Equation 1.11 (1)]; see also [16, p. 121, Equation 2.5 (1)])

$$
\Phi(z ; s ; a):=\sum_{k=0}^{1} \frac{z^{k}}{(k+a)^{s}}
$$

(a 2 C n Z

and $\tilde{A}(z)$ denotes the Psi (or Digamma) function defined by (see, for details, [1], [5], and [16])

$$
\tilde{\mathrm{A}}(\mathrm{z}):=\frac{\mathrm{d}}{\mathrm{dz}} \mathrm{f} \log \Gamma(\mathrm{z}) \mathrm{g}=\frac{\Gamma^{\mathrm{q}}(\mathbf{z})}{\Gamma(\mathbf{z})} \quad \text { or } \quad \log \Gamma(\mathbf{z})=\int_{1}^{\mathrm{z}} \tilde{\mathrm{A}}(\mathrm{t}) \mathrm{dt}:
$$

Since [1, p. 16, Equation 1.7.1 (10)]

$$
\tilde{\mathrm{A}}(\mathrm{z}+\mathrm{n})=\tilde{\mathrm{A}}(\mathrm{z})+\sum_{\mathrm{k}=1}^{\mathrm{n}} \frac{1}{\mathrm{z}+\mathrm{ki} 1} \quad(\mathrm{n} 2 \mathrm{~N}) ;
$$

we immediately have the relationship:

$$
\tilde{\mathrm{A}}(1+\mathrm{n}) \mathrm{i} \tilde{\mathrm{A}}(1)=\mathrm{H}_{\mathrm{n}} \quad\left(\mathrm{n} 2 \mathrm{~N}_{0}\right)
$$

with the harmonic numbers $\mathrm{H}_{\mathrm{n}}$ defined by (1.36). Thus, upon setting, $=\mathrm{i} \mathrm{n}$ (n $2 \mathrm{~N}_{0}$ ) in (3.7) and simplifying the resulting Hurwitz-Lerch Zeta function by means of the expansion formula (1.20), we find from (3.7) that

$$
\sum_{k=0}^{n}\left(\begin{array}{l}
n \\
k
\end{array}\right) H_{k} z^{k}=(1+z)^{n} H_{n} i \sum_{k=1}^{n} \frac{(1+z)^{k_{i} 1}}{n i k+1} ;
$$


or, equivalently,

$$
\sum_{k=0}^{n}\left(\begin{array}{l}
n \\
k
\end{array}\right) H_{n_{i} k} z^{k}=(1+z)^{n} H_{n} i \quad z^{n} \sum_{k=1}^{n} \frac{f(1+z)=z g^{k i} 1}{n i k+1}
$$

which, for $\mathrm{z} \nabla$ ! $c=(\mathrm{z} ; \mathrm{c})$, yields

$$
\sum_{k=0}^{n}\left(\begin{array}{l}
n \\
k
\end{array}\right)\left(\frac{c}{z i c}\right)^{k} H_{n i k}=\left(\frac{z}{z i c}\right)^{n} H_{n i}\left(\frac{c}{z i c}\right)^{n} \sum_{k=1}^{n} \frac{(z=c)^{k_{i} 1}}{n i k+1}
$$

We now substitute from (3.14) into the right-hand side of (3.4), and we get

$$
\begin{aligned}
\sum_{k=n+1}^{1} & \frac{\Gamma(k i n)}{k !}\left(i \frac{c}{z i c}\right)^{k} \\
= & \frac{(i 1)^{n}}{n !}\left(\frac{z}{z i c}\right)^{n}\left\{H_{n} i \log \left(\frac{z}{z i c}\right)\right\} \\
& i \sum_{k=0}^{n} \frac{(i 1)^{n}}{k !(n i k) !}\left(\frac{c}{z i c}\right)^{k} H_{n i k} \\
& \left(n 2 N_{0} ;\left|\frac{c}{z i c}\right|<1 ; c ; z 2 c\right) ;
\end{aligned}
$$

which, just as we observed above in our derivations of (2.3) and (2.6), is the simplified form of the assertion (1.37) of Theorem 3.

The general summation formula (3.6) can also be simplified in several special cases other than the case $\mathrm{I}=1$ when it yields the assertion (1.37) of Theorem 3. The details involved are being left as an exercise for the interested reader.

Next, by letting k 7 ! $k+n\left(\mathrm{n}_{2} \mathrm{~N}_{0}\right)$ on its left-hand side, and then setting

$$
3=\mathrm{i} \frac{\mathrm{C}}{\mathrm{Zi} \mathrm{C}} \text { and } 1 \mathrm{i}^{3}=1+\frac{\mathrm{C}}{\mathrm{Zi} \mathrm{C}}=\frac{\mathrm{z}}{\mathrm{Zi} \mathrm{C}}
$$

the summation formula (3.15) assumes the form:

$$
\begin{aligned}
\sum_{k=1}^{1} \frac{{ }^{k+n}}{k(k+1) \Phi \Phi థ(k+n)}= & \frac{(i 1)^{n}}{n !}\left(1 i^{3}\right)^{n} f H_{n} i \log \left(1 i^{3}\right) g \\
& i \sum_{k=0}^{n} \frac{(i 1)^{n+k}}{k !(n i k) !}{ }^{3 k} H_{n i k}
\end{aligned}
$$

(n $2 \mathrm{~N}_{0} ; \mathrm{j}^{3} \mathrm{j}<1$ ) 
or, equivalently,

$$
\begin{aligned}
\sum_{k=1}^{1} \frac{3 k+n}{k(k+1) \pitchfork \Phi థ(k+n)}= & \frac{(i 1)^{n}}{n !}\left(1 i^{3}\right)^{n} H_{n}+\frac{(i 1)^{n+1}}{n !}\left(1 i^{3}\right)^{n} \\
& \varnothing \log \left(1 i^{3}\right)+\sum_{k=0}^{n} \frac{(i 1)^{k+1}}{(n i k) ! k !} 3{ }^{n}{ }^{k} H_{k}
\end{aligned}
$$

(n $\left.2 \mathrm{~N}_{0} ; \mathrm{j}^{3} \mathrm{j}<1\right)$ :

Since

$$
\mathrm{H}_{0}=0 \quad \text { and } \quad \mathrm{H}_{\mathrm{k}}=1+\sum_{\mathrm{j}=2}^{\mathrm{k}} \frac{1}{\mathrm{j}} \quad \text { (k } 2 \text { Nnf 1g); }
$$

by the definition (1.36), it is readily observed that

$$
\begin{aligned}
& \sum_{k=0}^{n} \frac{(i 1)^{k+1}}{(n i k) ! k !} 3 n_{i} k_{H} H_{k}=\sum_{k=1}^{n} \frac{(i 1)^{k+1}}{(n i k) ! k !} 3 n_{i} k\left(1+\sum_{j=2}^{k} \frac{1}{j}\right) \\
& =\sum_{k=1}^{n} \frac{(i 1)^{k+1}}{(n i k) ! k !} 3^{n_{i} k}+\sum_{k=2}^{n} \frac{(i 1)^{k+1}}{(n i k) ! k !}\left(\sum_{j=2}^{k} \frac{1}{j}\right) 3 n_{i} k \\
& =\frac{3 n}{n !} i \frac{(i 1)^{n}}{n !}\left(1 i^{3}\right)^{n}+\sum_{k=2}^{n} \frac{(i 1)^{k+1}}{(n j k) ! k !}\left(\sum_{j=2}^{k} \frac{1}{j}\right) 3 n_{i} k \text { : }
\end{aligned}
$$

Upon substituting this last expression from (3.20) into the right-hand side of (3.18), if we make use of the second equation in (3.19) once again, we shall obtain

$$
\begin{aligned}
\sum_{k=1}^{1} \frac{3 k+n}{k(k+1) \Phi \notin \varnothing(k+n)}= & \frac{3 n}{n !}+\sum_{k=2}^{n} \frac{(i 1)^{k+1}}{(n i k) ! k !}\left(\sum_{j=2}^{k} \frac{1}{j}\right) 3 n_{i} k \\
& +\frac{(i 1)^{n}}{n !}\left(\sum_{j=2}^{n} \frac{1}{j}\right)\left(1 i^{3}\right)^{n} \\
& +\frac{(i 1)^{n+1}}{n !}\left(1 i^{3}\right)^{n} \phi \log \left(1 i^{3}\right)
\end{aligned}
$$

(n $\left.2 \mathrm{~N}_{0} ; \mathrm{j}^{3} \mathrm{j}<1\right)$;

provided that each side of (3.21) exists. 
The summation formula (3.21) happens to be the main result in a recent paper by Tu et al. [18, p. 6, Theorem 2]. Closed-form expressions for infinite series of the type occurring in (3.21) can also be found to be listed by Hansen [2, p. 174].

Finally, we remark that three summation formulas were derived recently by Nishimoto [9] by making use of the aforementioned operators of fractional calculus. His first main result $[9$, p. 2, Theorem 1]:

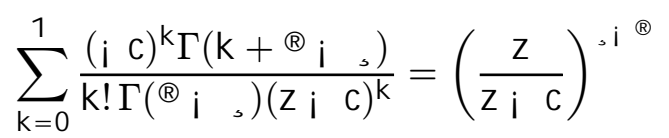

$$
\begin{aligned}
& \left(\left|\frac{\mathrm{C}}{\mathrm{zi} \mathrm{C}}\right|<1 ;\left|\frac{\Gamma\left(\mathrm{k}+\otimes_{\mathrm{i}}, \mathrm{s}\right)}{\Gamma\left(\otimes_{\mathrm{i}},\right)}\right|<1\right)
\end{aligned}
$$

is precisely the binomial expansion [cf. Equation (1.29) above]:

$$
\sum_{k=0}^{1} \frac{\left(1 / k_{k}\right.}{k !}{ }^{k}={ }_{1} F_{0}\left(1 / 2-;^{3}\right)=\left(1 i^{3}\right)^{i \frac{1}{2}}
$$

$$
\left(1 / 22 C ; j^{3} j<1\right)
$$

with

$$
1 / 2=\otimes_{i}, \quad \text { and } \quad 3=\mathrm{i} \frac{\mathrm{C}}{\mathrm{Zi} \mathrm{C}} \text { : }
$$

Nishimoto's second main result [9, p. 3, Theorem 2]:

$$
\sum_{\mathrm{k}=1}^{1} \frac{(\mathrm{i} \mathrm{c})^{\mathrm{k}}}{\mathrm{k}} \phi \frac{1}{(\mathrm{zi} \mathrm{c})^{\mathrm{k}}}=\log \left(\frac{\mathrm{z} \mathrm{i} \mathrm{c}}{\mathrm{z}}\right) \quad\left(\left|\frac{\mathrm{c}}{\mathrm{zi} \mathrm{c}}\right|<1\right)
$$

is simply the logarithmic series in (1.19) with $Z$ replaced by $C=(Z ; \quad c)$. And, if we denote the left-hand side of Nishimoto's third (and last) main result $[9$, p. 4 , Theorem 3]:

$$
\begin{aligned}
& \sum_{k=1}^{1}\left(i \frac{\mathrm{c}}{\mathrm{zi} C}\right)^{k} \phi \frac{\Gamma\left({ }^{\circledR} \mathrm{i} 1+\mathrm{k}\right)}{\mathrm{k} !} \mathrm{f}(\mathrm{k} ; \quad 1)(\mathrm{z} ; \quad b)+\circledast(\mathrm{c} ; \quad b) g
\end{aligned}
$$

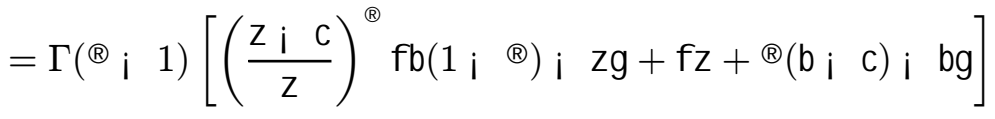

$$
\begin{aligned}
& \left(\mathrm{j} \Gamma\left(\Re_{\mathrm{i}} 1+\mathrm{k}\right) \mathrm{j}<1 \quad\left(\mathrm{k} 2 \mathrm{~N}_{0}\right) ;\left|\frac{\mathrm{C}}{\mathrm{zi} \mathrm{C}}\right|<1\right)
\end{aligned}
$$


by $\Lambda_{a ; b ; c}^{(\circledR)}(z)$, then we readily observe that

$$
\begin{aligned}
& \Lambda_{\mathrm{a} ; \mathrm{b} ; \mathrm{c}}^{(\mathrm{B})}(\mathrm{z}):=\sum_{\mathrm{k}=1}^{1}\left(\mathrm{i} \frac{\mathrm{c}}{\mathrm{zi} \mathrm{c}}\right)^{\mathrm{k}} \Phi \frac{\Gamma\left({ }^{\circledR} \mathrm{i} 1+\mathrm{k}\right)}{\mathrm{k} !} \mathrm{f}\left(\mathrm{k}_{\mathrm{i}} 1\right)(\mathrm{z} ; \quad b)+\circledast(\mathrm{c} ; \quad b) g \\
& =\left(\mathrm{z} \text { i b) } \sum_{\mathrm{k}=1}^{1}\left(\mathrm{i} \frac{\mathrm{c}}{\mathrm{zi} \mathrm{c}}\right)^{\mathrm{k}} \pitchfork \frac{\Gamma\left({ }^{\circledR} \mathrm{i} 1+\mathrm{k}\right)}{(\mathrm{ki} 1) !}\right.
\end{aligned}
$$

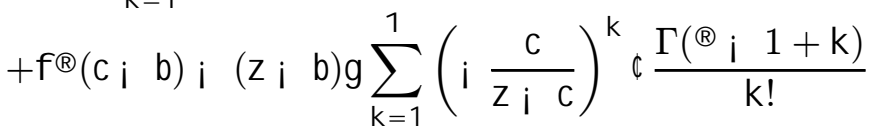

$$
\begin{aligned}
& =(\mathrm{z} \text { i b }) \sum_{\mathrm{k}=0}^{1}\left(\mathrm{i} \frac{\mathrm{c}}{\mathrm{zi} \mathrm{C}}\right)^{\mathrm{k}+1} \pitchfork \frac{\Gamma(\AA+\mathrm{k})}{\mathrm{k} !} \\
& +f \circledast(c ; \quad b) i \quad(z ; \quad b) g \sum_{k=1}^{1}\left(i \frac{c}{z i c}\right)^{k} \pitchfork \frac{\Gamma(\circledast i 1+k)}{k !}
\end{aligned}
$$

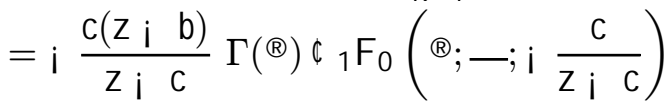

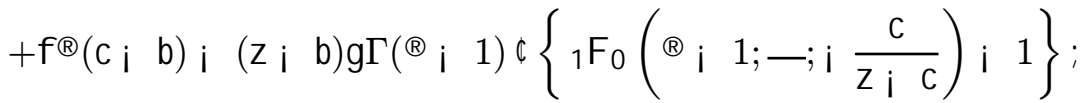

by employing the Pochhammer notation given by (1.23). Making use of the familiar binomial expansion (3.23) once again, we find from (3.26) that

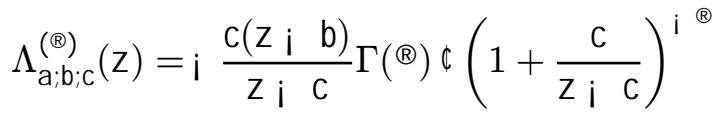

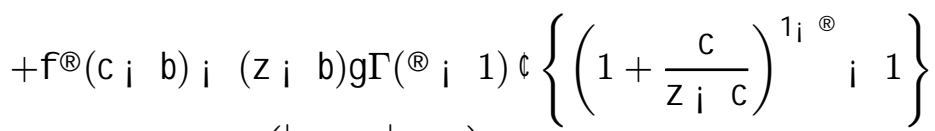

$$
\begin{aligned}
& \left(\left|\frac{\mathrm{C}}{\mathrm{Zi} \mathrm{C}}\right|<1\right) \text {; }
\end{aligned}
$$

that is,

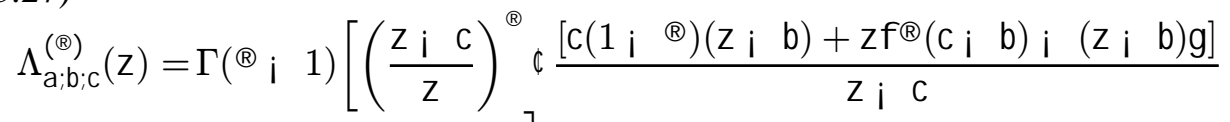

$$
\begin{aligned}
& +\mathrm{fz}+\mathbb{B}(\mathrm{b} ; \mathrm{c}) \text { i bg]; }
\end{aligned}
$$

which, after some simplification, leads us to the second member of the assertion (3.25), since

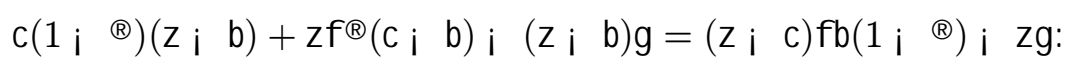




\section{ACKNOWLEDGEMENTS}

The present investigation was initiated and finalized during the third-named author's visits to Chung Yuan Christian University at Chung-Li in April 2001 and August 2001, respectively. This work was supported, in part, by the National Science Council of the Republic of China, the Faculty Research Program of Chung Yuan Christian University, and the Natural Sciences and Engineering Research Council of Canada under Grant OGP0007353.

\section{REFERENCES}

1. A. Erdélyi, W. Magnus, F. Oberhettinger, and F. G. Tricomi, Higher Transcendental Functions, Vol. I, McGraw-Hill Book Company, New York, Toronto, and London, 1953.

2. E. R. Hansen, A Table of Series and Products, Prentice-Hall, Englewood Cliffs, New Jersey, 1975.

3. R. Hilfer (Editor), Applications of Fractional Calculus in Physics, World Scientific Publishing Company, Singapore, New Jersey, London, and Hong Kong, 2000.

4. P. W. Karlsson, Hypergeometric functions with integral parameter differences, $J$. Math. Phys. 12 (1971), 270-271.

5. L. Lewin, Polylogarithms and Associated Functions, Elsevier (North-Holland), New York, London, and Amsterdam, 1981.

6. K. S. Miller and B. Ross, An Introduction to the Fractional Calculus and Fractional Differential Equations, A Wiley-Interscience Publication, John Wiley and Sons, New York, Chichester, Brisbane, Toronto, and Singapore, 1993.

7. K. Nishimoto, Fractional Calculus, Vols. I, II, III, IV, and V, Descartes Press, Koriyama, 1984, 1987, 1989, 1991, and 1996.

8. K. Nishimoto, An Essence of Nishimoto's Fractional Calculus (Calculus of the 21 st Century): Integrations and Differentiations of Arbitrary Order, Descartes Press, Koriyama, 1991.

9. K. Nishimoto, On some infinite sums obtained by $\mathrm{N}$-fractional calculus, J. Fract. Calc. 20 (2001), 1-6.

10. K. Nishimoto, I-C. Chen, and S.-T. Tu, Some families of infinite series summable by means of fractional calculus, Taiwanese J. Math. 6 (2002), 465-474.

11. K. Nishimoto, D.-K. Chyan, S.-D. Lin, and S.-T. Tu, On some infinite sums derived by $\mathrm{N}$-fractional calculus, J. Fract. Calc. 20 (2001), 91-97.

12. I. Podlubny, Fractional Differential Equations, Mathematics in Science and Engineering, Vol. 198, Academic Press, New York, London, Tokyo, and Toronto, 1999. 
13. A. P. Prudnikov, Yu. A. Brychkov, and O. I. Marichev, Integrals and Series (Supplementary Chapters), "Nauka," Moscow, 1986 (in Russian); see also Integrals and Series, Vol. 2: Special Functions (Translated from the Russian by N. M. Queen), Second Edition, Gordon and Breach Science Publishers, New York, 1988.

14. S. Salinas de Romero and H. M. Srivastava, Some families of infinite sums derived by means of fractional calculus, East Asian Math. J. 17 (2001), 135-146.

15. H. M. Srivastava, Generalized hypergeometric functions with integral parameter differences, Nederl. Akad. Wetensch. Indag. Math. 35 (1973), 38-40.

16. H. M. Srivastava and J. Choi, Series Associated with the Zeta and Related Functions, Kluwer Academic Publishers, Dordrecht, Boston, and London, 2001.

17. H. M. Srivastava, S. Owa, and K. Nishimoto, Some fractional differintegral equations, J. Math. Anal. Appl. 106 (1985), 360-366.

18. S.-T. Tu, I-C. Chen, and P.-Y. Wang, A certain family of infinite sums via fractional calculus, Chung Yuan J. 29 (2001), 5-8.

S.-D. Lin and S.-T. Tu

Department of Mathematics, Chung Yuan Christian University

Chung-Li, Taiwan 32023, R.O.C.

E-Mail: shyder@math.cycu.edu.tw sttu@math.cycu.edu.tw

H. M. Srivastava

Department of Mathematics and Statistics, University of Victoria

Victoria, British Columbia V8W 3P4

Canada

E-Mail: harimsri@math.uvic.ca 